\title{
Pseudosmittia fabioi sp. n., a new species from Sardinia (Diptera: Chironomidae, Orthocladiinae)
}

\author{
A. Boggero, ${ }^{1}$ S. Zaupa, ${ }^{1}$ B. Rossaro² \\ ${ }^{1}$ CNR-Institute of Ecosystem Study (ISE), Verbania Pallanza (VB); ${ }^{2}$ DeFENS Department of Food, \\ Environmental and Nutritional Sciences, University of Milano, Italy
}

\begin{abstract}
A new species of Pseudosmittia Edwards 1932, P. fabioi, from Sardinia (Palearctic region), is described and figured as male and female. The generic diagnosis is emended based on characters found in the new species. The species is characterized by a triangular anal point with microtrichia at apex (not projecting beyond tergite IX), an inferior volsella characterized by a rounded lobe with a setose accessory lobe adpressed to the gonocoxite, a well developed tooth-like projection on the outer margin of the gonostylus, the lack of acrostichals and an antenna with 6 flagellomeres in female.
\end{abstract}

\section{Introduction}

The genus Pseudosmittia Edwards, 1932, was recently revised (Ferrington \& Sæther, 2011), the genus is one of the representatives of the subfamily Orthocladiinae whose larvae are terrestrial or semiterrestrial (Strenzke, 1950). At present, 18 species belonging to the genus Pseudosmittia are reported in the European Fauna (Sæther \& Spies, 2013: http://www.faunaeur.org/) and elsewhere in the Western

Correspondence: Bruno Rossaro, DeFENS Department of Food, Environmental and Nutritional Sciences, University of Milano, via Celoria 2, I 20133 Milano, Italy. E-mail: bruno.rossaro@unimi.it

Key words: Pseudosmittia, Orthocladiinae, Chironomidae, Sardinia, Palaearctic region.

Acknowledgements: this study was partly funded by the EU (contract LIFE08/ENV/IT/000413 Local hydro-morphology, habitat and RBMPs: new measures to improve ecological quality in South European rivers and lakes INHABIT).

Received for publication: 20 August 2013

Revision received: 25 September 2013.

Accepted for publication: 17 October 2013.

(C) Copyright A. Boggero et al., 2014

Licensee PAGEPress, Italy

Journal of Entomological and Acarological Research 2014; 46:1892

doi:10.4081/jear.2014.1892

This article is distributed under the terms of the Creative Commons Attribution Noncommercial License (by-nc 3.0) which permits any noncommercial use, distribution, and reproduction in any medium, provided the original author(s) and source are credited.
Palaearctic 5 species are known from Algeria (Moubayed et al., 2006b), 10 from Turkey (Caspers \& Reiss, 1989) and 3 from Lebanon (Moubayed et al., 2006a). Ashe \& O'Connor (2012) listed 93 valid species occurring worldwide but since then 5 more species have been described including one from France (Langton, 2012), 3 from Argentina (Mauad et al., 2013) and 1 from South Korea (Ree, 2012). From the Russian Far East 13 species are known (Makarchenko \& Makarchenko, 2008). In the Oriental region 12 species are reported (Sæther, 2006; Ashe \& 0'Connor, 2012), 17 species from the Afrotropical (Freeman, 1956; Lehmann, 1979; Freeman \& Cranston, 1980; Ashe \& O'Connor, 2012); 26 species for the Neotropical (Spies \& Reiss, 1996; Andersen et al., 2010; Ashe \& 0'Connor, 2012; Mauad et al., 2013), 18 species from the Nearctic, 13 from Australasia and 15 from Oceania (Ashe \& 0'Connor, 2012). Some species previously included in Pseudosmittia have been transferred to other genera including Hydrosmittia Ferrington \& Sæther 2011, Lobosmittia Sæther \& Andersen, 1993 and Allocladius Kieffer, 1913 (Ferrington \& Sæther, 2011). The new West Palaearctic species from Sardinia (Italy), collected near the shore of a reservoir, is here described and figured as adult male and female. Pupa and larva of the new species are still unknown.

\section{Materials and methods}

Specimens were collected with a sweep net near the shore of the Bidighinzu reservoir (Sardinia, Italy) and preserved in alcohol $70^{\circ}$. Microscope slides were prepared by clearing specimens with $10 \% \mathrm{KOH}$ after separation of wings, followed by neutralization with glacial acetic acid, dehydration in phenol:xylene (3:1) and mounted in Canada Balsam after dissection of head, antennae, legs. Wings were mounted without clearing. Male and female genitalia were dissected and mounted in dorsal (male) and ventral (female) position. Morphological terminology and measurement follow Sæther (1980); all measurements are in $\mu \mathrm{m}$, except total body and wing length, which are in $\mathrm{mm}$, the values are rounded off to the nearest $1 \mu \mathrm{m}$ unless otherwise stated. The measurements, taken by the corresponding author, were compared with other descriptions (Ferrington \& Sæther, 2011). The type material is deposited in the collection of the Department of Food, Environmental and Nutritional Sciences (DeFENS) in University of Milano (Italy).

MATERIAL EXAMINED. Holotype male: ITALY: Sardinia, Sassari, Bidighinzu reservoir, 40 33' 24" N, 8 39' 44" W, 330 m a.s.l., maximum lake-depth $30 \mathrm{~m}$, 7.II.2011, sweep netting along lake shore, 13 paratype males, same locality, 1 allotype and 1 female, same locality, $\mathrm{S}$. Zaupa legit. Water temperature of the lake was $8^{\circ} \mathrm{C}$, pH 7.8, conductivity $411 \mu \mathrm{S} \mathrm{cm} \mathrm{cm}^{-1}$ at $20^{\circ} \mathrm{C}$.

ETYMOLOGY. Named in memory of the grandbaby of the senior author who died ten days after his birth. 


\section{Diagnostic characters}

The males of the new species can be easily included in the genus Pseudosmittia because of antenna without an apical seta, bare nonextended non-protruding eyes; wings and squama without setae, costa not extended, $\mathrm{Cu}_{1}$ sinuate, anal point not projecting beyond caudal margin of tergite IX.

P. fabioi sp. n. can be separated from all the other known species of the genus by the presence of a conspicuous tooth-like projection on the outer margin of the gonostylus, presence of an inferior volsella characterized by a spherical and transparent lobe, and an elongated - setose accessory lobe. The absence of acrostichals is also characteristic of this species. Other distinctive characters are: wing with a VR greater than one; postcubitus without bifurcation; mid-scutum without additional tubercle, hump or microtrichial tuft; male anal point placed forward on tergite IX, appearing as a median longitudinal ridge bearing few strong marginal setae, covered by a triangular plate with microtrichia on its surface, reaching to apex; spiniform, short, pale median virga present; female antenna with 6 flagellomeres, female genitalia with gonocoxite IX rounded; gonapophysis VIII divided into a small dorsomedian lobe, an apodeme lobe and a large ventrolateral lobe; spermathecal duct with loops.

\section{Description}

The species fits well within the diagnosis of Pseudosmittia (Cranston et al., 1989; Ferrington \& Sæther, 2011) except for the absence of acrostichals. Another important difference is the presence of six antennal segments in the female antenna, instead of 5 as described in Ferrington \& Sæther (2011) in other Pseudosmittia species, see Taxonomic remarks.

MALE. Measurements based on holotype.

Total body length $2.3-2.6 \mathrm{~mm}$, head wide $420-428$, wing length $1.5-1.7 \mathrm{~mm}$.

COLORATION. Brownish black.

HEAD. Antenna (Figure 1) with 13 flagellomeres, without apical seta, last flagellomere $368, \mathrm{AR}=0.80-0.86$, with 3-6 temporal setae (not separable into inner/outer verticals or postorbitals), palpomere lengths: $23,44.5,92,79$, and 93 .

THORAX. Antepronotum somewhat reduced, acrostichals absent, five dorsocentrals arising in a large white spot, another four small white spots (without setae) aligned with dorsocentrals: 4-8 scutellars and 3 prealars present.

WING. Figure 2: $1.729 \mathrm{~mm}$ long in holotype, costa not extended beyond $R_{4+5}, R_{2+3}$ at equal distance between $R$ and $R_{4+5}, R_{4+5}$ distal with respect to $\mathrm{M}_{3+4}, \mathrm{Cu}_{1}$ sinuate, postcubitus not bifurcate projecting well distal to $\mathrm{FCu}$. VR=1.38.

LEGS. Legs measurements are in Table 1. Spur of fore leg tibia 37 long, of mid leg 19 and 16, of hind leg 35 and 19. Spurs present on tarsomeres.
HYPOPYGIUM. Figure 3: anal point (Figure 4) present, placed anteriorly on tergite IX, not projecting beyond posterior margin, appearing as a longitudinal ridge, which bears a few robust, lateral setae, covered by a triangular plate rich in microtrichia reaching to apex; spiniform, short, pale median virga, about 20 long (Figure 5) present. Sternapodeme convex without anterior projections. Phallapodeme short, curved (Figure 3), aedeagal lobe small; superior volsella absent; inferior volsella (Figure 6) divided into two lobes, a principal lobe spherical, transparent, with microtrichia on its surface, an accessory lobe elongated, adpressed to gonocoxite, provided with setae. Gonostylus (Figure 7 ) with a very prominent tooth-like projection on the outer margin.

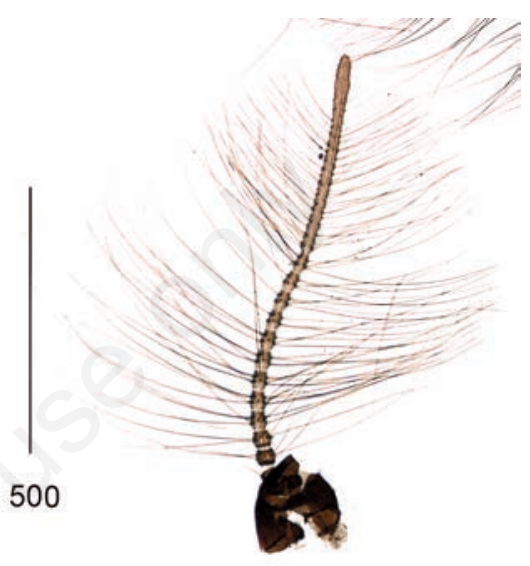

Figure 1. Pseudosmittia fabioi sp. n., male. Antenna. Measurements in micron in all figures.

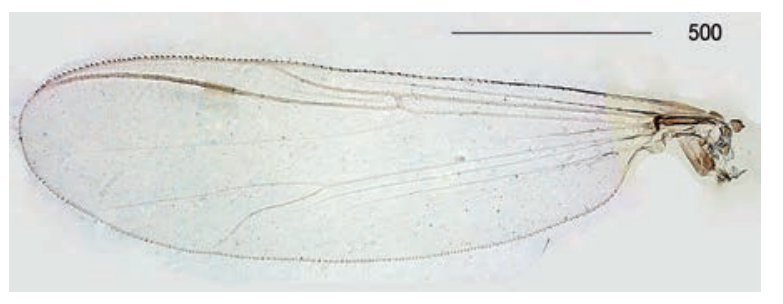

Figure 2. Pseudosmittia fabioi sp. n., male. Wing.

Table 1. Lengths (mean \pm stand. error in $\mu \mathrm{m})$ and proportions of legs of Pseudosmittia fabioi sp. $\mathbf{n}$. (male, $\mathbf{n}=3)$.

\begin{tabular}{|c|c|c|c|c|c|}
\hline & fe & ti & $\mathrm{ta}_{1}$ & $\mathrm{ta}_{2}$ & $\mathrm{ta}_{3}$ \\
\hline P1 & $547 \pm 17$ & $650 \pm 14$ & $306 \pm 12$ & $219 \pm 7$ & $125 \pm 3$ \\
\hline P2 & $585 \pm 13$ & $590 \pm 13$ & $271 \pm 6$ & $177 \pm 2$ & $115 \pm 6$ \\
\hline \multirow[t]{2}{*}{ P3 } & $595 \pm 9$ & $666 \pm 17$ & $348 \pm 13$ & $207 \pm 3$ & $173 \pm 6$ \\
\hline & $\mathrm{ta}_{4}$ & $\mathrm{ta}_{5}$ & LR & BV & SV \\
\hline P1 & $61 \pm 2$ & $61 \pm 1$ & 0.47 & 3.22 & 3.92 \\
\hline P2 & $46 \pm 3$ & $57 \pm 1$ & 0.46 & 3.65 & 4.33 \\
\hline P3 & $59 \pm 5$ & $53 \pm 1$ & 0.52 & 3.27 & 3.63 \\
\hline
\end{tabular}

fe, femur; ti, tibia; ta1-5, tarsomeres 1-5; LR, leg ratio, ratio of metatarsus to tibia; BV, Beinverhältnisse, combined length of femur, tibia, and basitarsus divided by combined length of tarsomeres 2-5; SV, Schenkel-Scheineverhältnis, ratio of femur plus tibia to metatarsus. 
FEMALE. Measurements based on allotype.

COLORATION. Brownish-black.

Total body length about $2.7 \mathrm{~mm}$, head width 408 , thorax length 742 , abdomen length $1.860 \mathrm{~mm}$, wing length $1.593 \mathrm{~mm}$. Wing length/length of profemur 3.9. Six antennal flagellomeres 37.1, 41.7, 39.4, 42.5, 49.2, 107.3; AR 0.51 in allotype. It is evident that the first and second flagellomere are well separated (Figure 8), while in many Pseudosmittia species they are fused, giving the appearance of 5 flagellomeres. Last antennal flagellomere without an apical seta, head with 5 setae not separable into inner or outer verticals, tentorium 14 wide.

Legs measurements are in Table 2.

Tergite IX of female not divided into two setigerous protrusions with about 15 setae and characteristic sclerotized margin against rounded and adpressed gonocoxites to each side. Gonocoxite without caudal projection, with 4 strong setae.

Gonapophysis VIII (Figure 9) divided into a large ventrolateral lobe, a small dorsomesal lobe widest in the middle and an apodeme lobe. Cerci of moderate size, 51 long, slightly more than half the length of the notum, 89 long. Seminal capsules ovoid, $86 \times 55$, with large neck; mostly pale, spermathecal ducts with loop, with small bulbs before opening.

Pupae and larvae unknown.

HABITAT. The specimens were collected with a sweep net in a meadow, near the shore of the Bidighinzu Reservoir in Sardinia, Italy. The species belongs to a terrestrial genus. The characteristic of the nearby reservoir are: water temperature $8^{\circ} \mathrm{C}, \mathrm{pH}=7.8$, conductivity $411 \mathrm{~S} \mathrm{~cm}^{-1}$ at $20^{\circ} \mathrm{C}$.

\section{Taxonomic remarks}

The new species fits well within the generic diagnosis of Pseudosmittia Edwards, 1932 and easily keys in this genus (Cranston et al., 1989), but it must be emphasized that all the observed male and female imagoes of $P$. fabio $i$ have no acrostichals so the species cannot be identified using the recent revision (Ferrington \& Sæther, 2011).

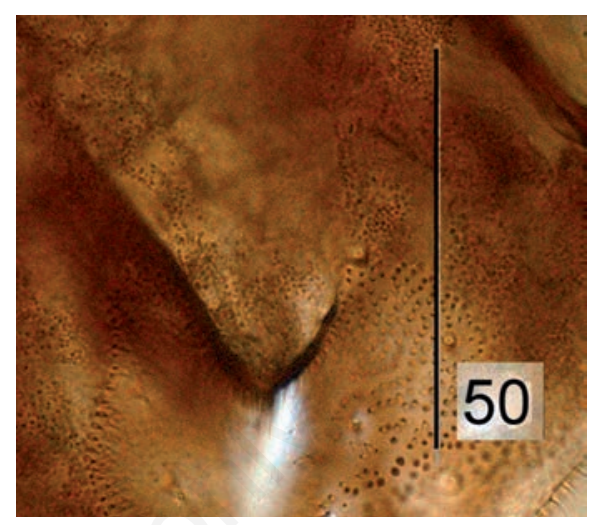

Figure 4. Pseudosmittia fabioi sp. n., male. Anal point.

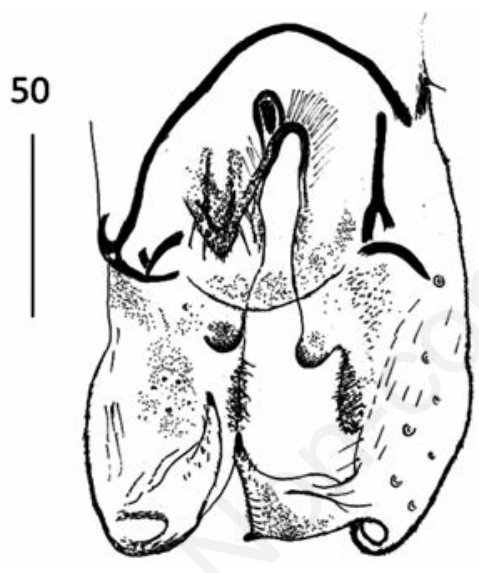

Figure 3. Pseudosmittia fabioi sp. n., male. Hypopygium.

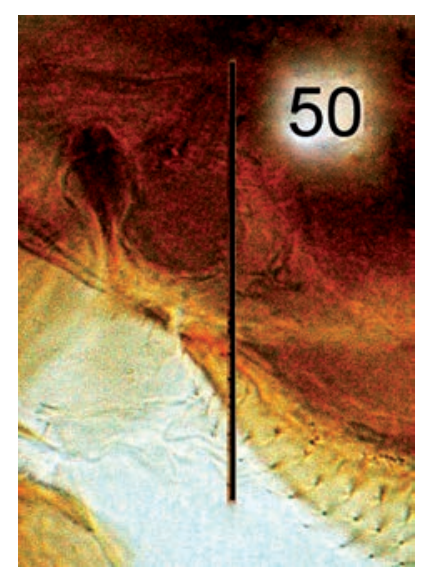

Figure 5. Pseudosmittia fabioi sp. n., male. Virga.

Table 2. Lengths (in $\mu \mathrm{m}$ ) and proportions of legs of Pseudosmittia fabioi sp. n. (female, n=1).

\begin{tabular}{|c|c|c|c|c|c|}
\hline & fe & ti & $\mathrm{ta}_{1}$ & $\mathrm{ta}_{2}$ & $\mathrm{ta}_{3}$ \\
\hline P1 & 402 & 465 & 203 & 130 & 80 \\
\hline P2 & 451 & 438 & 170 & 84 & 60 \\
\hline \multirow[t]{2}{*}{ P3 } & 462 & 490 & 245 & 112 & 105 \\
\hline & $\mathrm{ta}_{4}$ & $\mathrm{ta}_{5}$ & LR & BV & SV \\
\hline P1 & 45 & 44 & 0.44 & 3.58 & 4.27 \\
\hline P2 & 33 & 44 & 0.39 & 4.79 & 5.23 \\
\hline P3 & 37 & 50 & 0.50 & 3.94 & 3.89 \\
\hline
\end{tabular}

fe, femur; ti, tibia; ta1-5, tarsomeres 1-5; LR, leg ratio, ratio of metatarsus to tibia; BV, Beinverhältnisse, combined length of femur, tibia, and basitarsus divided by combined length of tarsomeres 2-5; SV, Schenkel-Scheineverhältnis, ratio of femur plus tibia to metatarsus. Note: Both basitarsus and metatarsus terms refer to the $1^{\text {st }}$ tarsomere. 


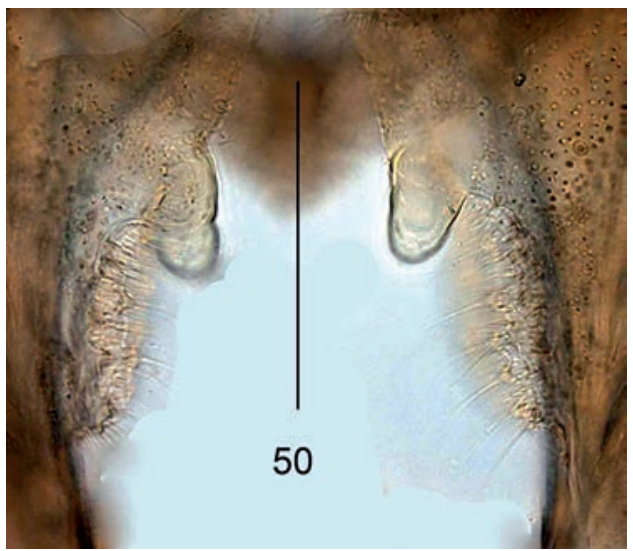

Figure 6. Pseudosmittia fabioi sp. n., male. Inferior volsella.

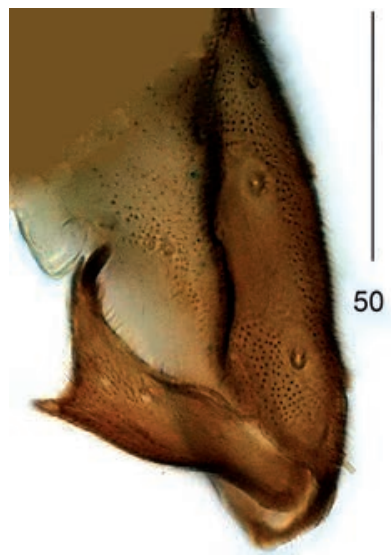

Figure 7. Pseudosmittia fabioi sp. n., male. Gonostylus.

The presence of at least 2 short, mostly biserial acrostichals on the midscutum was considered a diagnostic character in the recent revision of the genus (Ferrington \& Sæther, 2011), while in Cranston et al. (1989) it was stated that most species lack acrostichals, and this was considered a mistake in the recent revision of Ferrington \& Sæther (2011). It is here emphasized that in $P$. fabioi no acrostichals are present and this finding supports the conclusion that the presence of acrostichals is not a diagnostic character of the genus and the key to males of some orthoclads genera in Ferrington \& Sæther (2011) must be emended:

- Couplet 1, replace: ... 2-16 short with ... 0-16 short

- Couplet 4, replace ... With 2 acrostichals with ... With 0-2 acrostichals. Another important point that must be here emphasized is the presence of 6 antennal flagellomeres in the female of $P$. fabioi, while other species of the genus are described with 5 antennal flagellomeres (Ferrington \& Sæther, 2011).

\section{References}

ANDERSEN T., SÆTHER 0.A., MENDES H.F., 2010 - Neotropical Allocladius Kieffer, 1913 and Pseudosmittia Edwards, 1932 (Diptera: Chironomidae). - Zootaxa 2472: 1-77.

ASHE P., O'CONNOR J.P., 2012 - A World Catalogue of Chironomidae (Diptera). Part 2. Orthocladiinae. Irish Biogeographical Society and National Museum of Ireland, Dublin, 968 pp.

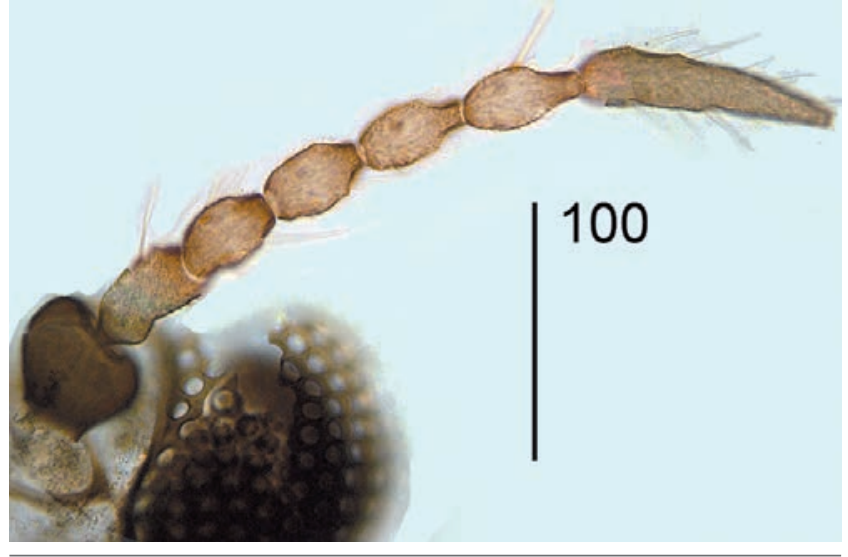

Figure 8. Pseudosmittia fabioi sp. n., female. Antenna.

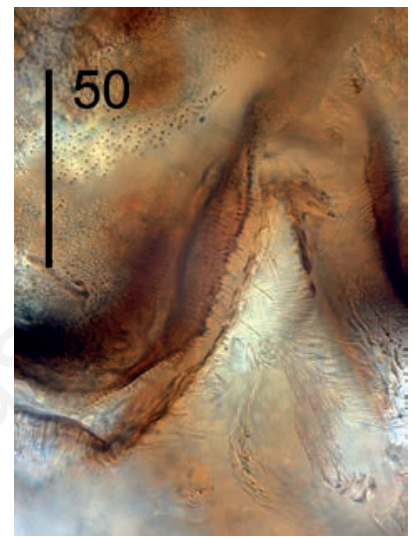

Figure 9. Pseudosmittia fabioi sp. n., female. Genitalia, detail of gonapophysis VIII.

CASPERS N., REISS F., 1989 - Die Chironomiden der Turkei. Teil I: Podonominae, Diamesinae, Prodiamesinae, Orthocladiinae (Diptera, Nematocera, Chironomidae). - Entomofauna 10: 105-160. CRANSTON P.S., OLIVER D.R., SÆTHER 0.A., 1989 - The adult males of Orthocladiinae (Diptera: Chironomidae) of the Holarctic region Keys and diagnoses. In: WIEDERHOLM T. (Ed.). Chironomidae of the Holarctic region. Part 3. Adult males. Entomologica Scandinavica, Supplement 34: 165-352.

FERRINGTON L.C., SÆTHER 0.A., 2011 - A revision of the genera Pseudosmittia Edwards, 1932, Allocladius Kieffer, 1913, and Hydrosmittia gen. n. (Diptera: Chironomidae, Orthocladiinae). Zootaxa 2849: 1-314.

FREEMAN P., 1956 - A study of the Chironomidae (Diptera) of Africa south of the Sahara. Part II. - Bull. Br. Mus. Nat. Hist. Ent. 4: 287-368.

FREEMAN P., CRANSTON P.S., 1980 - 11. Family Chironomidae. In: CROSSKEY R.W. (Ed.). Catalogue of the Diptera of the Afrotropical region. Publ. Trust. Brit. Mus. (Nat. Hist.) 1437: 175-202.

LANGTON P.H., 2012 - Two new species of Orthocladiinae (Diptera, Chironomidae) from south-eastern France. - Dipterists Digest (Second Series) 19: 135-141.

LEHMANN J., 1979 - Chironomidae (Diptera) aus Fließgewässern Zentralafrikas (Systematik, Ökologie, Verbreitung und Pro-duktions-biologie). Teil I: Kivu-Gebiet, Ostzaire. - Spixiana, Supplement 3: 1-144.

MAKARCHENKO E.A., MAKARCHENKO M.A., 2008 - Review of the genus Pseudosmittia Edwards 1928 (Diptera: Chironomidae: 
Orthocladiinae) from the Russian Far East. - Russian Entomol. J. 17: 217-228.

MAUAD M., SIRI A., DONATO M., 2013 - New species of Pseudosmittia Edwards, 1932 and new records of Allocladius Kieffer, 1913 (Diptera: Chironomidae, Orthocladiinae) from South America. Zootaxa 3694: 445-460.

MOUBAYED-BREIL J., DIA A., 2006a - Espèces de Chironomes nouvelles pour la faune du Liban et du Proche-Orient [Diptera, Chironomidae]. - Ephemera 8: 101-107.

MOUBAYED-BREIL J., LOUNACI A., LONACI-DAUDI D., 2006b - Non biting midges from Algeria, North Africa [Diptera, Chironomidae]. Ephemera 8: 93-99.

REE H.I., 2012 - Eight new and four newly recorded species of Chironomidae (Insecta: Diptera) from Korea. - Anim. Syst. Evol. Divers. 28: 241-260.

SÆTHER 0.A., 1980 - Glossary of chironomid morphology terminology
(Diptera: Chironomidae). - Entomologica Scandinavica, Supplement 14: 1-51.

SÆTHER 0.A., 2006 - Japanese Pseudosmittia Edwards (Diptera: Chironomidae). - Zootaxa 1198: 21-51.

SÆTHER 0.A., ANDERSEN T., 1993 - Lobosmittia, a new genus of orthoclads from Tanzania and Turkey (Diptera: Chironomidae). Tijdschr. Entomol. 136: 283-287.

SPIES M., REISS F., 1996 - Catalog and bibliography of Neotropical and Mexican Chironomidae (Insecta, Diptera). - Spixiana, Supplement 22: 61-119.

SÆTHER 0.A., SPIES M., 2013 - Fauna Europaea: Chironomidae. In: BEUK P., PAPE T. (eds.). Fauna Europaea: Diptera Nematocera. Fauna Europaea version 2.4. [Available from: http://www.faunaeur.org

STRENZKE K., 1950 - Systematik, Morphologie und Ökologie der terrestrischen Chironomiden. - Archiv Hydrobiol. Suppl. 18: 207-414. 